\title{
AVALIAÇÃO DAS MUDAS DE MAMOEIRO SOB O EFEITO DA APLICAÇÃO DE DIFERENTES COMPOSIÇÕES DE BIOFERTILIZANTES
}

Felipe da Costa WECKNER ${ }^{(1)}$

Milton César Costa CAMPOS ${ }^{(2)}$

Ediana Pereira do NASCIMENTO ${ }^{(3)}$

Bruno Campos MANTOVANELLI ${ }^{(4)}$

Maílson Ferreira NASCIMENTO ${ }^{(5)}$

\author{
${ }^{1}$ Graduando em Agronomia pela Universidade Federal do Amazonas, Campus Vale do Rio Madeira; \\ E-mail: felipec.weckner@gmail.com; \\ ${ }^{2}$ Professor Dr. Adjunto III da Universidade Federal do Amazonas, Campus Vale do Rio Madeira; \\ E-mail: mesarsolos@gmail.com; \\ ${ }^{3}$ Eng. ${ }^{\circ}$ Agr ${ }^{\circ}$,pela Universidade Federal do Amazonas, Campus Vale do Rio Madeira; \\ E-mail:ediana.agronomia@gmail.com; \\ ${ }^{4}$ Eng. ${ }^{\circ}$ Agr ${ }^{\circ}$, pela Universidade Federal do Amazonas, Campus Vale do Rio Madeira; \\ E-mail:brunomantovanelli21@gmail.com; \\ ${ }^{5}$ Graduando em Agronomia pela Universidade Federal do Amazonas, Campus Vale do Rio Madeira; \\ E-mail: mailsonnf@gmail.com.
}

Recebido em: 09/09/2015 - Aprovado em: 04/05/2016 - Disponibilizado em: 30/07/2016

\begin{abstract}
RESUMO: O mamoeiro HAVAÍ (Carica papaia.) é uma das plantas frutíferas mais difundidas nacionalmente, tornando o Brasil representante de cerca de $30 \%$ da produção mundial do fruto. O presente trabalho teve o objetivo de avaliar o efeito da aplicação de diferentes composições de biofertilizantes nas mudas de mamoeiro. O experimento foi realizado em casa de vegetação, no Instituto de Educação, Agricultura e Ambiente da Universidade Federal do Amazonas, Campus de Humaitá, AM. O delineamento experimental utilizado foi em blocos casualizados, com cinco tratamentos e quatro repetições, cuja os tratamentos foram: 1) testemunha, sem aplicação de biofertilizante; 2) biofertilizante puro, composto com $100 \%$ de esterco bovino fresco; 3) biofertilizante composto com $75 \%$ de esterco bovino fresco $+25 \%$ de caroço de açaí fresco triturado; 4) biofertilizante composto com $50 \%$ de esterco bovino fresco + $50 \%$ de caroço de açaí fresco triturado e; 5) biofertilizante composto com $25 \%$ de esterco bovino fresco $+75 \%$ de caroço de açaí fresco triturado. Foram avaliados os parâmetros número de folhas, diâmetro do caule, altura das plantas, massa fresca da parte aérea, massa fresca e seca das raízes. Os dados coletados foram submetidos à análise de variância (teste F), e teste tukey ao nível de $5 \%$ de probabilidade, no programa estatístico (Assistat versão 7.7 beta). As variáveis alturas de plantas e número de folhas responderam satisfatoriamente à aplicação do biofertilizante com predominância de esterco bovino.
\end{abstract}

Palavras chaves: Mamão. Biofertilizante. Mudas. Estercobovino.

\section{Evaluation of papaya seedlings under the effect of applying different compositions of biofertilizers}

\begin{abstract}
HAWAII papaya (Carica papaya.) Is one of the most widespread fruit plants nationally, making Brazil represented about $30 \%$ of world production of the fruit. This study aimed to evaluate the effect of applying different compositions of biofertilizers in papaya seedlings. The experiment was conducted in a greenhouse at the Institute of Education, Agriculture and Environment of the Federal University of Amazonas, Campus de Humaita, AM. The experimental design was a randomized block, with five treatments and four replications, whose treatments were: 1) control without the application of biofertilizers; 2) pure biofertilizer, composed $100 \%$ of fresh cattle manure; 3) compound bio-fertilizer with $75 \%$ of fresh cattle manure $+25 \%$ lump crushed fresh acai; 4) compound bio-fertilizer with $50 \%$ of fresh cattle manure $+50 \%$ core and crushed fresh acai; 5) bio-fertilizer compound $25 \%$ of fresh cattle manure $+75 \%$ lump crushed fresh acai. They evaluated the parameters number of leaves, stem diameter, plant height, fresh weight of shoot, fresh and dry roots. The collected data were submitted to analysis of variance (F test) and Tukey test at 5\% probability, the statistical program (Assistat version 7.7 beta). The variables plant height and number of leaves satisfactorily responded to the application of biofertilizers with predominance of cattle manure.
\end{abstract}

Key Words:Papaya. Biofertilizers. Seedlings. Cattlemanure 


\section{Introdução}

O Brasil está entre os três maiores produtores mundiais de frutas, com uma produção anual superior a 40 milhões de toneladas, estima-se que a cadeia produtiva das frutas abrange três milhões de hectares e gera seis milhões de empregos diretos, evidenciando a importância da fruticultura no agronegócio brasileiro (SEAB/DERAL, 2013). Dentre estas, o mamoeiro HAVAÍ (CaricapapayaL.) é uma das plantas frutíferas mais difundidas nacionalmente, sendo o Brasil responsável por cerca de $30 \%$ da produção mundial de mamão (CANTILLIANO et al., 2005). O mamoeiro (CaricapapayaL.) pertence à família Caricaceae, é uma planta herbácea, vigorosa e de alta produtividade, típica de clima tropical, bem adaptada ao nordeste brasileiro, região esta que comporta áreas de clima semiárido, caracterizado por apresentar baixo potencial de matéria orgânica nos solos, reduzindo a qualidade do mesmo (SEVERINO et al., 2006).

Para se obter produções satisfatórias no cultivo de mamão, uma das etapas principais é o preparo de mudas, processo este que visa plantas com altos potenciais produtivos. Porem a produção de mudas onera os custos de implantação do pomar, devido a gastos com o estabelecimento da estrutura inicial como casa de vegetação, recipientes, sistema de irrigação entre outros custos. Então, afim de diminuir estes custos, bem como a dependência do mercado de insumos em especial o de substratos prontos, é preciso investir em tecnologias alternativas que além de sustentáveis, melhorem a rentabilidade do produtor (DANNER et al., 2007).

Com essa necessidade de se obter um sistema de produção de mudas frutíferas com alto potencial produtivo é de extrema importância aliar-se a agricultura orgânica, com ênfase para o uso de biofertilizante, buscando obter o máximo de benefícios sociais, considerando a ética, a cidadania, a auto sustentação, a redução ou diminuição da dependência de insumos e energia não renovável e a preservação do meio ambiente, através da melhor utilização dos recursos naturais e sócio econômico disponível (HAMERSCCHMIDT et Al., 2000). O adubo orgânico biofertilizante é o nome dado ao efluente líquido resultante da fermentação anaeróbica e/ou aeróbica em biodigestores de resíduos vegetais e animais. Independentemente do tipo de fermentação, a decomposição do material provoca mudanças no material de origem, acelerando a disponibilidade dos nutrientes para as plantas atuando direto ou indiretamente, sobre todo ou partes das plantas, elevando sua produtividade (MAYER, 2001).

Para Penteado. (2004), a utilização do biofertilizante, deve ser estimulada tanto na pulverização das plantas como aplicação direta nos solos. Nas plantas o efeito do uso de biofertilizantes é muito eficiente no 
controle de pragas e doenças, na aceleração de crescimento e estado nutricional da planta, na literatura o uso do biofertilizante nos solos é menos frequente, mas podem contribuir para melhoria física e promover a produção de substâncias húmicas que exercem expressiva importância na fertilidade do solo com reflexos positivos na produção (DELGADO et al., 2002). Como as informações sobre a avaliação de mudas de mamoeiro sobe o efeito de aplicações de biofertilizantes são escassas. O Presente trabalho teve o objetivo de investigar o efeito da aplicação de diferentes composições de biofertilizante nas mudas de mamoeiro.

\section{Materiais e métodos}

$\mathrm{O}$ experimento foi conduzido no período de janeiro a junho de 2013, no viveiro de produção de mudas do Instituto de Educação, Agricultura e Ambiente da Universidade Federal do Amazonas, situado no município de Humaitá, AM, estando situado sob as seguintes coordenadas geográficas de $7^{\circ} 30^{\prime} 56^{\prime}$ ' latitude Sul e $63^{\circ} 1^{\prime}$ ' 35" longitude Oeste. O clima da região, segundo a classificação de Köppen é do tipo tropical chuvoso, temperaturas variando entre 25 e $27{ }^{\circ} \mathrm{C}$ e precipitação média anual de $2.500 \mathrm{~mm}$, com período chuvoso iniciando em outubro e prolongando-se até junho, apresentando umidade relativa do ar entre 85 e $90 \%$.

Para o preparo do biofertilizante puro foi utilizado esterco bovino fresco, coletado nas propriedades rurais do município. No preparo de $120 \mathrm{~L}$ de biofertilizante puro, foram adicionado $15 \mathrm{~L}$ de esterco bovino fresco, em 50 L de água, uma semana após, mais $10 \mathrm{~L}$ do esterco fresco ecompletado o volume para $120 \mathrm{~L}$ em recipiente com capacidade para 180 L, mantendoohermeticamente fechado durante trinta dias ou mais, dependendo da atividade microbiana(SANTOS,2002).

Sendo que os demais tratamentos foram formados através da substituição de parte do esterco bovino fresco por caroço de açaí fresco triturado em triturador elétrico, as porcentagens da substituição estão descritas abaixo:

1) Testemunha (sem aplicação de biofertilizante)

2) Biofertilizante puro $(100 \%$ de esterco bovino fresco)

3) Biofertilizante 1(composto com $75 \%$ de esterco bovino fresco $+25 \%$ de caroço de açaí fresco triturado)

4) Biofertilizante 2 (composto com $50 \%$ de esterco bovino fresco $+50 \%$ de caroço de açaí fresco triturado)

5) Biofertilizante 3 (composto com $25 \%$ de esterco bovino fresco $+75 \%$ de caroço de açaí fresco triturado).

O solo utilizado para a produção das mudas foi denominado um CambissoloHáplico coletado na camada de 0 a $20 \mathrm{~cm}$, o qual foi corrigido com calcário para a elevação do $\mathrm{pH}$ para próximo de 5,5 
mantendo-se úmido por 60 dias. As sementes foram coletadas de frutos de mamão HAVAÍ sadios e semeadas em sacos de polietileno com capacidade para 3 litros de substrato. Foram semeadas 3 sementes por sacos a uma profundidade de $1,5 \mathrm{~cm}$. Após a emergência foi realizado o desbaste das plantas aos $4 \mathrm{~cm}$ de altura, deixando a planta mais vigorosa por saco.

Para o ensaio foram utilizado o delineamento em blocos casualizados $5 \times 4$ com 4 repetições, totalizando 80 unidades experimentais. As aplicações dos biofertilizantes iniciaram após o desbaste das plântulas e foram realizados a cada sete dias, utilizando um litro de biofertilizantes diluídos em cinco litros de água, aplicados aos finais de tarde, as avaliações nas plantas foram feitas a cada 20 dias e as variáveis avaliadas foram:

Altura da planta (AP) - altura da muda, medida desde o colo da muda até o ápice da última folha com auxílio de uma régua melimetrada;

Número de folhas (NF) - realização da contagem do número de folhas;

Diâmetro do caule (DC) - medido $1 \mathrm{~cm}$ acima do nó formado logo acima da superfície do solo do recipiente, com auxílio de um paquímetro;

Matéria fresca da raiz(MFR) método da estufa de circulação forçada de ar a $65^{\circ} \mathrm{C}$, por 24 horas;
Matéria seca da parte aérea (MSPA): Foi retirada a parte aérea das plantas de cada tratamento para secagem em estufa de circulação forçada de ar à $65^{\circ} \mathrm{C}$ até atingirem peso constante, ocasião em que foi procedida à pesagem em balança eletrônica semianalítica.

Os dados obtidos foram submetidos à análise de variância (teste $F$ ), teste tukey ao nível de 5\% de probabilidade no programa estatístico (Assistat versão 7.7 beta).

\section{Resultados e discussões}

A partir dos resultados apresentados na tabela 1 , observa-se que houve diferenças significativas a partir do teste $\mathrm{F}$ apenas para as variáveis alturas de plantas e número de folhas, enquanto que as demais varáveis não foram influenciadas pelos diferentes tratamentos aplicados a base das diferentes concentrações.

Em relação a variável altura de plantas, evidenciou-se que o tratamento T2 a base de esterco bovino puro apresentou os melhores resultados quando comparados aos demais tratamentos, no entanto, as plantas de mamoeiro conseguiram obter valores de altura entre 14,94 e 20,81 cm no $\mathrm{T} 1$ e $\mathrm{T} 2$ respectivamente. Tal fato mostra que $o$ biofertilizante a base de esterco bovino exerce efeitos positivos sobre o crescimento das plantas, devido às melhorias físicas e químicas, promovida pelas substâncias húmicas, resultando em maior ajustamento osmótico pela planta, e posterior absorção de 
água pelo seu sistema radicular (Liang et al. 2005). Constata-se que o T2 promoveu um aumento de $40 \%$ no seu crescimento em altura quando equiparado ao tratamento que não recebeu o biofertilizante. De fato, esse comportamento está coerente com Mesquita et al. (2012) ao avaliarem efeito da irrigação em águas salinas em solo com aplicação de biofertilizante bovino.

Os tratamentos T3, T4 e T5 referente a variável altura de plantas foram significativamente diferentes quando comparados ao T2, evidenciando assim que a adição de diferentes concentrações de caroço de açaí triturado não evidenciou maior crescimento das mudas de mamoeiro, desta forma, a adição deste material na produção de biofertilizante não indica em maiores ganhos em crescimento, tal resultado pode ser equiparado com Galvão et al. (2007), no qual não encontrou ganhos em crescimento avaliando o desempenho de mudas de mamoeiro sob diferentes substratos orgânicos, tendo o caroço de açaí triturado em uma das composições.

Os resultados obtidos para a variável número de folhas, novamente evidenciam a influência do T2 nos melhores resultados de desenvolvimento quando comparados aos demais tratamentos. Observa-se um aumento superior a $100 \%$ quando comparado o T2 $(7,89)$ ao $\mathrm{T} 1(3,76)$, no entanto, o maior número de folhas no tratamento T2 pode estar correlacionado as maiores disponibilidades dos nutrientes essênciais a planta ao qual o esterco bovino apresenta, apresentando influência na emissão e no tamanho de folhas (Hoffmann et al. 2001), influenciando diretamente na taxa de fotoassimílados, regulando o crescimento das plantas. Todavia, o biofertilizante $\mathrm{T} 2$ poder ser uma alternativa viável para o produtor, em consenso com Sá et al. (2013) ao afirmarem que a substituição parcial de adubos minerais industrializados pelosbiofertilizante na solução nutritiva para o cultivo do mamoeiro resulta em produtividades adequadas.

Em contraste com os demais tratamentos T3, T4 e T5, o T2 mostrou se também eficientemente melhor e mais indicado para esta variável número de folhas, evidenciando assim a não influencia do caroço de açaí triturado nos ganhos de produção de folhas.

(Tabela 1). Analise de variânciados tratamentos nas seguintes variáveis analisadas de crescimento e desenvolvimento das mudas de mamoeiro sob o efeito da aplicação de diferentes composições de biofetilizantes.

\begin{tabular}{crrrrrr}
\hline Tratamentos & MSR(g) & MFR(g) & MSPA(g) & ALP (cm) & DC(mm) & NF \\
\hline T1 & $0,26 \mathrm{a}$ & $1,25 \mathrm{a}$ & $0,34 \mathrm{a}$ & $14,94 \mathrm{c}$ & $5,93 \mathrm{a}$ & $3,76 \mathrm{~b}$ \\
T2 & $0,26 \mathrm{a}$ & $1,65 \mathrm{a}$ & $0,35 \mathrm{a}$ & $20,81 \mathrm{a}$ & $6,40 \mathrm{a}$ & $7,89 \mathrm{a}$ \\
\hline
\end{tabular}




\begin{tabular}{ccccccc}
\hline T3 & $0,31 \mathrm{a}$ & $1,45 \mathrm{a}$ & $0,33 \mathrm{a}$ & $16,25 \mathrm{bc}$ & $5,87 \mathrm{a}$ & $4,60 \mathrm{~b}$ \\
$\mathbf{T 4}$ & $0,32 \mathrm{a}$ & $2.15 \mathrm{a}$ & $0,34 \mathrm{a}$ & $17,48 \mathrm{bc}$ & $6,27 \mathrm{a}$ & $4,46 \mathrm{~b}$ \\
$\mathbf{T 5}$ & $0.31 \mathrm{a}$ & $2,11 \mathrm{a}$ & $0,40 \mathrm{a}$ & $18,60 \mathrm{bc}$ & $5,67 \mathrm{a}$ & $4,73 \mathrm{~b}$ \\
$\mathrm{CV} \%$ & 23.88 & 25,25 & 34,68 & 7,34 & 17,32 & 11,24 \\
\hline
\end{tabular}

T1: testemunha, T2:100\% de esterco bovino, T3:75\% de esterco bovino, T4:50\% de esterco bovino+50 de caroço de açaí, T5:25\% de esterco bovino $+75 \%$ de caroço de açaí. Médias seguidas de mesma letra na coluna não diferem estatisticamente entre si pelo teste Tukey a $5 \%$ de probabilidade.

\section{Conclusão}

As variáveis altura de plantas e número de folhas responderam satisfatoriamente a aplicação do biofertilizante com predominância de esterco bovino fresco.

\section{Referências bibliográficas}

CANTILLIANO, R. F. F.; CASTAÑEDA, L. M. F. Análise comparativa da logística de exportação de frutas do Brasil e do Chile. In: MARTINS, D. S (ed). Papaya Brasil: mercado e inovações tecnológicas para o mamão. Vitória: Incaper, p.25-39. 2005.

DANNER, M.A.; CITADIN, I.; JUNIOR, A.A.F.; ASSMANN, A.P.; MAZARO, S.M.; SASSO, S.A.Z. Formação de mudas de jabuticabeira (Plinia sp.) em diferentes substratos e tamanhos de recipientes. Revista Brasileira Fruticultura, v.29, n.1.2007.

DELGADO, A.; MADRID, A.; KASSEM, S.; ANDREU, L.; CAMPILLO, M. C. aplicação de esterco e de biofertilizantes e substâncias húmicas via fertirrigaçãov.245, p. 277-286. 2002.

Galvão, R. O.; Araújo Neto, S. E.; Santos, F. C. B.; Silva, S. S. 2007. Desempenho De Mudas De Mamoeiro Cv. Sunrise Solo Sob Diferentes Substratos Orgânicos. Revista Caatinga, 20:144-151.
MESQUITA, F.O; RODRIGUES, R.M; MEDEIROS, R.F; CAVALCANTE, L.F; BATISTA, R.O. Crescimento inicial de Caricapapayasob irrigação com águas salinas em solo com biofertilizante bovino. Semina: Ciencias agrarias, Londrina, v. 33, p. 2689-2704, 2012.

Hoffmann, I.; Gerling, D.; Kyogwom, U. B.; Manebielfeldt, A. 2001. Farmers management strategies to maintain soil fertility in a remote area in northwest Nigeria. Agriculture, Ecosystems\&Environment, 86:263-275. HAMERSCHMIDT, I; SILVA, J.C.B.V; LIZARELLI, P.H; Agricultura orgânica. Curitiba: EMATER-PR, 68p. 2000.

Liang. Y. C.; SI, J.; Nikolic, M.; Peng, Y.; Cheng, W.; Jiang, Y. 2005. Organic manurestimulates biological activity barley growth in soil subject to secondary salinization. Soilbiologyandbiohemestry. Acta Horticulturae, 37:1185-1195.

PENTEADO, S, R.; PRIMAVESI, TENTRIN, A, R.; A Fruticultura Orgânica: formação e condução. Viçosa: Aprenda Fácil, 308p. 2004.

\section{SEVERINO L. S; LIMA, R. L.; BELTRÃO}

N. E. M. Composição Química de Onze Materiais Orgânicos Utilizados em Substratos para Produção de Mudas. Comunicado técnico 27, EMBRAPA, Campina Grande-PB, 2006.

Sá, F. V. S.; Mesquita, E. F.; Bertino, A. M. P.; Silva, G. A.; Costa, J. D. 2013.

Biofertilizantes na produção hidropônica de mudas de mamoeiro. Revista Verde de 
Agroecologia e Desenvolvimento Sustentável, 8:109-116.

SANTOS. A.C.V.; FILHO, G.N.; VIDOR, C. Solubilização de fosfatos por microrganismos na presença de fontes de carbono. Revista

Brasileira de Ciência do Solo, n.24, p. 311319, 2000.

SEAB/DERAL. Fruticultura - Análise da conjuntura agropecuária. Disponível em: <http://www.Agricultura.pr.gov.br/arquivos/F ile/deral/Prognosticos/fruticultura_2012_ 13.pdf>. 25 abr. 2013. 